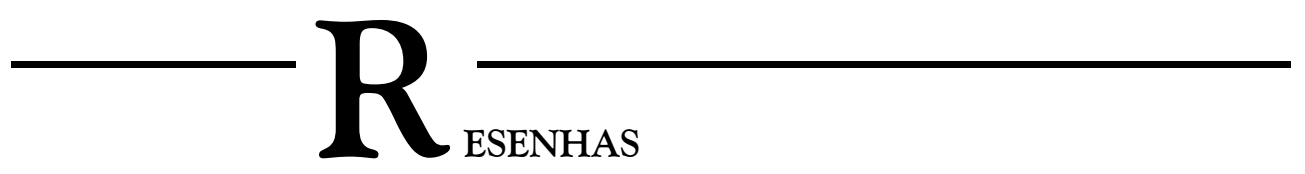

GALINKIN, Ana Lúcia. A Cura no Vale do Amanhecer. Brasília: TechnoPolitik, 2008, 152 pp.

\title{
Tia Neiva e sua magia: cura e ritual no Vale do Amanhecer
}

\section{Amurabi Pereira de Oliveira}

O obra de Ana Lúcia Galinkin é fruto de sua pesquisa de mestrado realizada no ano de 1977. Sua publicação em 2008 foi influenciada em parte, como a própria autora explica, pelo centenário de Claude Lévi-Strauss, cujos textos "O feiticeiro e sua magia" e "A eficácia simbólica" nortearam sua pesquisa sobre a cura no Vale do Amanhecer. De lá para cá muitas mudanças ocorreram, o movimento cresceu e se expandiu, Tia Neiva, a líder espiritual, faleceu, bem como o movimento Nova Era tomou outras proporções no país. No entanto, o trabalho de Galinkin continua eximiamente atual, seja pelo seu valor etnográfico, que possibilita ao leitor uma imersão no universo do Vale do Amanhecer como poucas etnografias permitem, realizando o esforço de comprovar o "estar lá" nos dizeres de Geertz" (2005), seja também pelo esforço teórico em analisar uma prática ritual que envolve a cura espiritual a partir principalmente do arcabouço estruturalista.

O Vale do Amanhecer foi fundado em Planaltina, cidade satélite de Brasília, 
no final dos anos 1960, por Neiva Chaves Zelaya, mais conhecida como "Tia Neiva", que aos 33 anos passou a ter visões de uma entidade denominada "Pai Seta Branca", que teria sido em sua última vida um índio tupinambá, mas que em vidas anteriores teria sido São Francisco de Assis, um jaguar, e, antes mesmo, teria vindo de outro planeta, a bordo de uma espaçonave. Nessa breve digressão biográfico-mitológica da entidade espiritual mais importante do movimento ${ }^{2}$ percebemos o forte sincretismo religioso aí presente. A observação é interessante pois ao contrário de outros autores que preferem utilizar o termo sincretismo para se referenciar ao Vale (Cavalcante $2005^{3} ; 2000^{4}$; Oliveira $\left.{ }^{5} 2008\right)$, Galinkin utiliza mais o termo bricolagem, sendo mais fiel a sua proposta teórica. De fato, o que se percebe é uma complexa bricolagem entre os mais diversos elementos, que se utilizam do catolicismo, do espiritismo, da umbanda, bem como da Nova Era (Oliveira ${ }^{6} 2009$ ).

A descrição do movimento, ou doutrina, como preferem os adeptos, é extremamente rica, tendo destaque não apenas a descrição da dinâmica social e organização religiosa como também o aspecto que tange à liderança que apresenta um modelo que a autora chama de bicéfala, sendo dividida entre Tia Neiva, a líder carismática e Mário Sassi, seu esposo, o líder racional. Segundo a autora: "o carisma da líder sagrada é mantido através de revelações e de novas ordens do sobrenatural no sentido de promover inovações" (Galinkin 2008:43) Ao passo que caberia a seu cônjuge o domínio burocrático e formal do movimento - relação que é detalhadamente analisada no segundo capítulo do livro.

Para a compreensão desse complexo universo místico-religioso a autora nos fornece uma porta de entrada para a cosmologia do Vale, destacando que sua dinâmica se dá em torno da execução das atividades rituais de curas espirituais e desenvolvimento mediúnico, que no entender dos adeptos é a função última do lugar, já que teria sido fundado a fim de preparar a humanidade para o terceiro milênio. Tal sentido por um lado confere ao movimento um caráter milenarista, mas por outro também o situa dentro da Nova Era, já que essa preparação para o terceiro milênio, bem como a crença numa utopia "nova erista" nos permite situá-lo junto ao universo da Nova Era (Medeiros $\left.{ }^{7} 1998\right)^{-}$o que, em nosso entender, é a principal lacuna do trabalho da autora, ao destacar a influência do espiritismo e da umbanda e olvidar o New Age.

Também é destacado o caráter inovador do movimento, afinal como aponta Carvalho $^{8}$ (1999), esse movimento formula possivelmente o universo religioso mais complexo de que já se teve notícias. Por mais que realize uma bricolagem processase uma ressignificação de muitos elementos que são trazidos, como a ideia de carma, que perde o seu sentido fatalístico para ganhar um significado mais plástico, podendo ser sublimado através do desenvolvimento mediúnico, através do ingresso na doutrina, e o posterior trabalho de caridade (oferta de trabalhos espirituais), e, mais que isso, pela ideia de livre arbítrio, o carma pode ser entendido como uma escolha do espírito que pretende expiar suas dívidas mais rapidamente. 
Também são ressignificadas as entidades que compõem o panteão do Vale, sendo hierarquizadas basicamente em dois grupos: Espíritos de Luz: formados por pretos velhos, caboclos, médicos espirituais e capelinos (dentre outras entidades que não se enquadrariam aí); e Espíritos das Trevas: formados por elítrios, cobradores (que podem ser encarnados ou desencarnados), exus, sofredores e obsessores. O primeiro grupo possibilita o desenvolvimento mediúnico e ajuda os médiuns em seus trabalhos, ao passo que as entidades do segundo, além de atrapalharem o desenvolvimento mediúnico, são apontadas como principais causadores das doenças espirituais.

Como a dinâmica da cura espiritual está focada nos serviços ofertados pelos médiuns, que podem ser do tipo apará, que se vincula à incorporação, ou doutrinador, que se vincula às demais atividades, Galinkin dá uma especial atenção a essa temática, sistematizando as peculiaridades desses tipos de médiuns, bem como sua relação com os chamados pacientes. Assim como na análise de Lévi-Strauss ${ }^{9}$ (1967), a autora coloca o médium num lugar em que caberá ao mesmo ordenar a experiência daquele que busca os seus serviços, sendo pela manipulação de símbolos e rituais que o médium realizará tal tarefa.

A imersão nesse universo bricolado, que permite ao paciente experienciar uma sensação de déjà $v u$, viabiliza a socialização que torna a experiência eficaz. Em verdade, a análise da autora parte do postulado de Lévi-Strauss de que a eficácia simbólica se faz possível na medida em que há uma crença por parte do xamã em seus poderes mágicos, daquele que procura seus serviços e do consenso na comunidade.

Apesar de haver uma forte explicação místico-religiosa para as doenças, essas são subdivididas em dois tipos: materiais, cujos agentes devem ser tratados por médicos comuns; e espirituais, que demandam o tratamento oferecido pelo Vale. Há, porém, a possibilidade de haver doenças causadas por um conjunto de fatores, de modo que o tratamento tradicional deve ser acompanhado do tratamento espiritual. Sejam as doenças causadas por elítrios, obsessores, exus, sofredores ou cobradores, em todos os casos se trata de uma obsessão, que pode se revelar nos sintomas do alcoolismo, da loucura, ou mesmo de problemas afetivos e familiares. Há ainda o caso de doenças que são fruto de dívidas cármicas, muitas vezes uma escolha do próprio espírito, que busca expiar mais rapidamente suas dívidas.

Outro ponto forte no trabalho de Galinkin está no exame minucioso da ligação estabelecida entre os agentes causais das doenças espirituais e o paciente. Algumas doenças podem se dar quando há uma relação entre o obsediado e o agente, bem como pode haver uma afinidade em termos de comportamentos ou mesmo de atitude. Cada tipo de agente causal é movido por uma espécie de sentimento distinto, que vai do amor ao ódio. Essas relações também podem ser simplificadas em dois tipos: as doenças programadas, que ocorrem quando a pessoa optou pela doença grave, ou pela encarnação, ou mesmo pela sujeição ao assédio de cobradores; e as doenças não programadas, que ocorrem quando a pessoa tinha uma ligação com o espírito (no caso, agente obsessor ou sofredor), ou não aceita Cristo (no caso do exu), ou ainda 
quando ela se entrega ao vício ou a atos vis (quando o agente é um obsessor).

Essa análise nos permite visualizar como a doença e a cura são constituídas socialmente, e que a relação estabelecida no processo ritual entre médium e paciente visa justamente a ordenar a experiência e decodificar os símbolos que são articulados no momento ritual. A autora também explora as diversas acepções que o termo "cura" vai tomando dentro do movimento, tanto entre os adeptos como entre os frequentadores, ou pacientes, de modo que são mais recorrentes as significações ligadas ao ritual denominado cura bem como à remissão parcial ou total dos sintomas físicos de algo que motivou a ida ao Vale.

Por fim, a autora busca situar o Vale do Amanhecer com relação principalmente às influências sofridas por parte do espiritismo e da umbanda, trabalho que é realizado de forma bastante clara e direta. Vale ressaltar, porém, que outras possibilidades poderiam ter sido postas, em especial, a tensão que se estabelece entre tais credos, uma vez que como aponta Brandão ${ }^{10}$ (2004), o candomblé, a umbanda e o espiritismo formam uma gradação no Brasil, ligada obviamente às relações sociais e étnicas neles vivenciadas no país.

O fenômeno apontado por Ortiz ${ }^{11}$ (1999), em torno do embranquecimento da umbanda, esclarece a forma como tais relações se situam de modo tenso. Ainda que não tenha sido esse seu foco, Galinkin nos dá pistas de como os elementos oriundos do espiritismo demandam um grau menor de ressiginificação para possuírem legitimidade frente aos adeptos e pacientes, em oposição àqueles oriundos da umbanda.

Para Galinkin, o paciente ao entrar no processo ritual do Vale do Amanhecer completa uma relação triangular necessária para ocorrer o processo de cura, relação essa que envolve:

O paciente obsediado, que sofre a ação dos espíritos e transmite os sinais de seu mal ao apará, mediador entre os homens e os espíritos, que codifica os sintomas do paciente nos símbolos da Doutrina, e o médium doutrinador, que decodifica as mensagens espirituais e os símbolos da Doutrina para o paciente, ao mesmo tempo em que encaminha o espírito obsessor para o Astral Superior (Galinkin 2008:121, grifos da autora).

Percebamos que a ideia de codificação e de recodificação que se faz presente no trabalho da autora guia-se essencialmente pela noção de substrato proposta por Lévi-Strauss, uma vez que tal processo se liga diretamente à necessidade de ressocialização do paciente afim de que o mesmo compartilhe do consenso coletivo em torno da eficácia simbólica dos rituais realizados, bem como busque construir ou reforçar a crença subjetiva desse sujeito nessa eficácia, já que a crença por parte do médium já existe (deixando claro que o paciente de hoje pode vir a ser o médium de amanhã, e que normalmente é assim que dinâmica se dá).

Como já foi dito, trata-se de uma pesquisa realizada há cerca de três décadas, 
mas que mantém sua atualidade, seja fornecendo material para aqueles que procuram pesquisar sobre o Vale do Amanhecer, seja para aqueles que, de modo mais genérico, buscam compreender os fenômenos ligados às curas espirituais nos mais diversos movimentos religiosos. Sua rica descrição etnográfica serve de guia para um processo de imersão do leitor no universo pesquisado, de modo que podemos ter uma visualização clara da compreensão cosmogônica e das hierarquias simbólicas existentes.

Fica por fim o desafio para os demais pesquisadores de avançar na discussão, seja em relação à discussão sobre curas, ou em relação à bricolagem realizada nos mais diversos movimentos religiosos, em especial naqueles que estão situados no universo da Nova Era, cuja principal característica está justamente na capacidade de retirar os elementos de seus contextos originários e utilizá-los de forma performática.

\section{Notas}

1 GEERTZ, Clifford. (2005), Obras e vidas: o antropólogo como autor. Rio de Janeiro: Editora UFRJ.

2 Por mais que hierarquicamente se coloque abaixo de Jesus Cristo, sua imagem se confunde por vezes com o próprio (cf. a tese de doutorado em Sociologia de Gláucia Buratto Rodrigues de Mello, Millenarismes brésiliens: contribuition à l'étude de l'imaginaire contemporain), porém sua presença e referência iconográfica se faz mais presente no movimento de modo geral.

3 CAVAlCANTE, Carmen Luisa Chaves. (2005), Dialogias no Vale do Amanhecer: Os Signos de um Imaginário Religioso Antropofágico. São Paulo: Tese de Doutorado em Comunicação e Semiótica, Pontifícia Universidade Católica.

4. (2000), Xamanismo no Vale do Amanhecer: c caso Tia Neiva. São Paulo: Annablume.

5 OLIVEIRA, Amurabi Pereira de. (2008), Dinâmicas culturais e relações de reciprocidade no Vale do Amanhecer: um estudo de caso sobre o templo de Campina Grande - PB. Campina Grande: Dissertação de Mestrado em Ciências Sociais, UFCG.

6 ___ (2009), "Nova Era à brasileira: a New Age popular do Vale do Amanhecer". Inter. Cult. Com. Vol. 4, no 5: 31-48.

7 MEDEIROS, Bartolomeu Tito Figueirôa de. (1998), "Um caso de sincretismo afro-cristãokardecista-umbandista-new age: as casas filiais do Vale do Amanhecer, no nordeste brasileiro". XXI Reunião brasileira de antropologia. GT 31, Perspectivas antropológicas da religião. Vitória, Espírito Santo.

8 CARVALHO, José Jorge. (1999), "Um espaço público encantado. Pluralidade religiosa e modernidade no Brasil”. Série Antropológica, no 249 . Disponível em http://www.unb.br/ics/dan/ Serie249empdf.pdf. Acesso em 30 de março de 2010.

9 LÉVI-STRAUSS, Claude. (1967), Antropologia estrutural. Rio de Janeiro: Tempo Brasileiro.

${ }^{10}$ BRANDÃO, Carlos Rodrigues. (2004), "Fronteira da fé: alguns sistemas de sentido, crenças e religiões no Brasil de hoje”. Estudos Avançados, Vol. 18, no 52: 261-288.

${ }^{11}$ ORTIZ, Renato. (1999), A morte branca do feitiçeiro negro. São Paulo: Brasiliense.

Amurabi Pereira de Oliveira (amuarabi_cs@hotmail.com) Licenciado e Mestre em Ciências Sociais (UFCG), Doutor em Sociologia (UFPE) e Professor do Programa de Pós-Graduação em Sociologia da Universidade Federal de Alagoas. 